Article

\title{
Recognising the Significance of Bioethical Reflections for the Promotion of Teachers' Health in Higher Education: A Cross-Sectional Study
}

\author{
Ivaní Nadir Carlotto 1,* and Maria Alzira Pimenta Dinis ${ }^{2}$ \\ 1 UFP Energy, Environment and Health Research Unit (FP-ENAS), University Fernando Pessoa (UFP), Praça \\ 9 de Abril 349, 4249-004, Porto, Portugal; 33163@ufp.edu.pt \\ 2 UFP Energy, Environment and Health Research Unit (FP-ENAS), University Fernando Pessoa (UFP), Praça \\ 9 de Abril 349, 4249-004, Porto, Portugal; madinis@ufp.edu.pt \\ * Correspondence: 33163@ufp.edu.pt; Tel.: +55-51-980-112223 (I.N.C)
}

\begin{abstract}
This research is part of the Doctoral thesis "Perceptions of university professors on Health Promotion and Sustainability: a research proposal based on Health Promoting Universities (HPU) / World Health Organization (WHO) ", University Fernando Pessoa (UFP) / Porto - Portugal, authored by Ivaní Nadir Carlotto: (1) Background: Universities are essential institutions for health promotion (HP). Bioethics, as a transversal discipline, seeks to analyse and systematise these values in an ethical way, strengthening the synergy between health and HP. Ecological models are a possibility to develop health actions in a holistic, sustainable and salutogenic way, stimulating positive aspects related to ethics, well-being and quality of life; (2) Methods: Exploratory-descriptive methodology and quantitative-qualitative approach. Sample: Teachers from 9 higher education institutions (HEI), random sample, probabilistic for convenience, CI $=95 \%, n=1400$ persons; (3) Results: Production of 6 main components through Factorial Analysis categorized and interpreted by Qualitative Content Analysis and MAXQDA ${ }^{\circledR}$ software; (4) Conclusions: Universities function as research and learning venues to strengthen HP's activities. Bioethics and HP aim to build qualified actions in health, to defend and promoting well-being, quality of life, equity, inclusion, sustainability and social justice, with the proper conceptual clarity that distinguishes it.
\end{abstract}

Keywords: bioethics; health promotion; higher education

\section{Introduction}

Higher Education Institutions (HEI) are essential to develop the implementation of programs aimed to Health Promotion (HP). Since they have its own ethos and different cultures, they act as optimizers of the conceptual aspects of the HP and of cross-disciplinary values such as, equality, social justice and sustainable development (SD) (Dooris, 2006; Dooris et al, 2017). Bioethics arises as an important intervention tool when considering the ethical challenges presented in the professors' daily life and in the health practices in the HEI, since, under this perspective of attention and permanent protection, bioethics promotes and reinforces complete practices in health, pointing to the necessary actions in HP teaching, respecting the HPU guidelines and benchmarks. By fitting the autonomy, beneficence and justice principles in the HP teaching, such as in the proposals presented in this thesis, bioethics promotes, to professors, the inclusive sense of health, providing them a social perspective and contemplating the necessary social responsibility issue to the understanding, planning and the HP action implementation of HP actions in HEI (Carlotto and Dinis, 2018c; Garrafa, 2005a).

\section{Bioethics as a transversal contribution to the promotion of teacher health}

In the early 1970s, the concept of bioethics mirrored a new approach to ethical and scientific advances in biology and medicine (Belmont Report, 1978). Since then, the understanding about bioethics differs according to the context in which it is inserted, allowing a pluralism of conceptions and 
concepts from the applied ethics (Garrafa, 2005b; Mandal et al, 2017; Oliveira, 2012). In the evolutionary context of its construction over time, it is possible to list three epistemological pillars that support the principles of bioethics: (i) the prevalence of a multi-inter-transdisciplinary structure, making it possible to expand analyzes linked to diverse knowledge centres, starting with interpretation of multiple factors, i.e., scientific and technical, social knowledge and concrete reality; (ii) respect for the moral pluralism of societies and nations; (iii) understanding of the unfeasibility of the existence of universal bioethical paradigms, making it necessary to use tools of approximation with the different societal references (Garrafa, 2005a; Santana and Garrafa, 2013). The initial concept of bioethics was related to the ethical question of preservation of the planet and its biodiversity, in the face of technological advances that could cause harm to the ecosystem. Against this background, bioethics would incorporate references about their perception of the quality of human life, such as respect for the environment and ecosystem, as well as existing biomedical issues (Garrafa, 2005a).

For the American Van Rensselaer Potter, precursor of the term Bioethics in his book "Bioethics: A Bridge to the Future" (Potter, 1971), Bioethics would contribute to the formation of a new discipline, extending a bridge between two cultures, that is, sciences and humanities, which did not dialogue, making possible scientific development with ethical vigilance.

The approach of Bioethics with HP in its different areas of practice, specifically in the case study of this thesis, which focuses on the HP of higher education (HE) teachers, reaffirms the understanding that, in order to articulate Health, HP and Bioethics it is necessary to reflect on human quality of life, preservation of ecology and biodiversity, finiteness of natural resources, balance of the ecosystem, concern for sustainability, inclusion, equity, justice, dignity, among others (Azetsop, 2011; Carlotto and Dinis, 2017b; Carlotto and Dinis, 2018a; Dooris, 2006; Garrafa, 2005b; Parker et al, 2007; Real de Asúa and Herreros, 2016; Sanz, 2016).

Siqueira-Batista et al. (2015) argues that bioethics should be considered as the ethics of science that combines humility, responsibility and competence with an interdisciplinary and cross-cultural approach and that allows the real meaning of humanity to prevail. Zoboli (2010), on the other hand, considers that bioethics encompasses advances in biotechnology, health care and professional ethics, including these factors in a contextualized and expanded way, focused on the complexity of life itself and problematizing them in the search for possible solutions. In health care, bioethics creates bridges between being and doing professional, between the institutional and public policy universe, allowing an interface between achievement, duty and what should do, where the scope of responsibility prevails as the guiding principle of an ethical horizon (Zoboli, 2010). In this context, since public health and bioethics include the social and subjective determinants in their analysis, it is feasible to conduct the actions in HP through an expanded and complex view of human and health attitudes. In this sense, based on the concepts developed by Vidal, Gomes and Siqueira-Batista (2015), bioethics, directed to action research in the HP field, requires advances made by research on the central ethical problems experienced.

For the same authors, ethical problems arise from factors such as the lack of articulation between intersectoral public policies, reduced access to health services or social and economic heterogeneities. These authors also point out that bioethical challenges are evident when tensions are established between technical-scientific and practical knowledge, hindering a reflexive analysis of the presented question, in all the dimensions in which it manifests itself. Bioethics has two epistemological characteristics: an approach with more ecological aspects, as recommended by Potter (1971), and another method of more clinical aspects, as evidenced by Hellegers and Ramsey (1973). In this way, it is possible to identify two paradigms of research involving bioethical discipline: one of hermeneutical and critical importance that investigates the interpretation of the cultural assumptions of the use of biotechnologies and the other, more casuistic, that seeks concrete resolutions for the dilemmas. Both are epistemologically complementary and need each other. Bioethics as a case study emerged in the 1970s, part of this vision being two globally recognized paradigms: the principialistic paradigm and the casuistic paradigm (Junges, 2006). 


\subsection{Principialistic Paradigm of Bioethics}

The mainstream theory, published in the Belmont Report (1978) and highlighted in the Principles of Biomedical Ethics, first published in 1979 and then reprinted seven times to date, was based on four basic bioethical principles (Beauchamp and Childress, 1979). This theory was conceived to serve as an accessible and practical instrument for the analysis of conflicts arising in the field of bioethics, namely: (i) beneficence; (ii) non-maleficence; (iii) equity and (iv) autonomy (García, 2013; Garrafa, 2005b). Other principles may be derived and related to accumulated theory on bioethics, HP and also used in the application of evidence in public health interventions, such as the principles of respect, solidarity, sustainability, social responsibility, participation, transparency and accountability of interventions in public health, contributing to the construction of a model of health interventions informed by evidence and an ethical perspective (Junges, 2014). Beauchamp and Childress (1979) postulate that bioethical principles are not framed as absolute truths, but prima facie, that is, they become evident, valid and customary in the first analysis of the case, in the absence of another more decisive principle. Bioethics, in this context, emerged as the concern with establishing moral criteria for human behaviour, in a scenario in which a multifaceted factorial concept influences life. Thus, human rights appear as ethical references in support of bioethics in actions to protect life and HP. Along the same lines, the United Nations Educational, Scientific and Cultural Organization (UNESCO, 2005), on October 19, 2005, in Paris, through the Universal Declaration of Bioethics and Human Rights (UDBHR), a conceptual framework on bioethics, since, in addition to confirming its pluralistic and interdisciplinary character, it provides a definitive extension of its agenda on the biomedical-biotechnology theme for the social and environmental fields (Snead, 2009). Thus, UDBHR (UNESCO, 2005) began to incorporate, in addition to the careful analysis of the social and ecological aspects of the 21st century, the historical work cited above, resulting in critical conceptual changes in the context of bioethics.

Table 1 presents a synopsis/schedule of the documents that contributed to the formulation and sedimentation of UDBHR. This documentary schedule seeks to reinforce the general sense of health, the first idea that permeates the understanding of the Declarations and documents highlighted here. It should be noted that UDBHR was designed to conform to classical bioethical principles, giving them social and collective perspective, whose scope is allied to the expanded notion of the concept of health.

In this context, it is essential to emphasize that this new conceptual reference of Bioethics involved in UDBHR acts as a tool that provides a broader range of possibilities for action, and that incorporates the fields of social bioethics and environmental bioethics, promoting, in turn, the conceptual reference essential for the attainment of a bioethics genuinely committed to the situations of human and planetary life (Garrafa, 2005b; Santana and Garrafa, 2013). Thus, became part of the UDBHR in their chapter on "Principles", among other documents, the following specific articles concerning the universal ethics proposed by the authors mentioned above (Azetsop, 2011; Carlotto and Dinis, 2017b; Dooris, 2006; Garrafa, 2005b; Junges, 2014; Parker et al., 2007; Real de Asúa and Herreros, 2016; Sanz, 2016), and that contributed to the diffusion and establishment of bioethics as a universal discipline: human dignity and human rights (Article 3); respect to human vulnerability and individual integrity (Article 8); equality, justice and equity (Article 10); respect for cultural diversity and pluralism (Article 12); solidarity also, cooperation (Article 13); social responsibility and health (Article 14); sharing of benefits (Article 15); protection of the environment, biodiversity and the biosphere (Article 17) (UNESCO, 2005). Undoubtedly, it can be verified that this new perspective of bioethics established from the UDBHR (UNESCO, 2005) has positively and adequately impacted in universal ethical discussions. It can conclude that the product of this approach focuses on the implementation of qualified processes of actions in health, social inclusion, equity, justice, development and sustainability (Carlotto and Dinis, 2017b; Dooris, 2016; Doran et al., 2017; Duarte-Cuervo, 2015). 
Table 1. Timeline referring to the UDBHR formulation, adapted from Garrafa (2005b), Junges (2014), Matisonn (2017), Santana and Garrafa (2013) and UNESCO (2005).

\begin{tabular}{|c|c|}
\hline Year & Base Documents \\
\hline 1945 & UNESCO Charter \\
\hline 1948 & Universal Declaration of Human Rights \\
\hline 1964 & $\begin{array}{l}\text { Declaration of Helsinki by the World Medical Association } \\
\text { on the Ethical Principles Applicable to Medical Research on } \\
\text { Human Rights }\end{array}$ \\
\hline 1965 & $\begin{array}{l}\text { United Nations International Convention on the } \\
\text { Elimination of All Forms of Racial Discrimination }\end{array}$ \\
\hline 1966 & $\begin{array}{l}\text { International Covenant on Economic, Social and } \\
\text { Cultural Rights and International Covenant on Civil and } \\
\text { Political Rights }\end{array}$ \\
\hline 1974 & $\begin{array}{l}\text { UNESCO Recommendation Concerning the Status of } \\
\text { Scientific Researchers }\end{array}$ \\
\hline 1978 & $\begin{array}{l}\text { UNESCO Recommendation Concerning the Status of } \\
\text { Scientific Researchers }\end{array}$ \\
\hline 1982 & $\begin{array}{l}\text { International Guiding Principles on the Ethics of } \\
\text { Biomedical Research on Human Subjects adopted by the } \\
\text { Council of International Organizations of Medical Sciences }\end{array}$ \\
\hline 1989 & United Nations Convention on the Rights of the Child \\
\hline 1989 & $\begin{array}{l}\text { ILO Convention No } 169 \text { on Indigenous and Tribal Peoples } \\
\text { in Independent Countries }\end{array}$ \\
\hline 1992 & United Nations Convention on Biological Diversity \\
\hline 1993 & $\begin{array}{l}\text { General Rules on Equal Opportunities for Persons with } \\
\text { Disabilities }\end{array}$ \\
\hline 1995 & $\begin{array}{l}\text { Agreement on Trade-Related Aspects of Intellectual } \\
\text { Property Rights (TRIPS), an annexe to the Marrakesh } \\
\text { Agreement Establishing the World Trade Organization }\end{array}$ \\
\hline 1997 & $\begin{array}{l}\text { Universal Declaration on the Human Genome and Human } \\
\text { Rights }\end{array}$ \\
\hline 1997 & $\begin{array}{l}\text { Convention for the Protection of Human Rights and } \\
\text { Dignity of Human Beings with regard about the } \\
\text { Application of Biology and Medicine, the Convention on } \\
\text { Human Rights and Biomedicine of the Council of Europe }\end{array}$ \\
\hline 1997 & $\begin{array}{l}\text { UNESCO Declaration on the Responsibilities of } \\
\text { Generations Present for Future Generations }\end{array}$ \\
\hline 2001 & UNESCO Universal Declaration on Cultural Diversity \\
\hline 2001 & $\begin{array}{l}\text { International Treaty on Plant Genetic Resources for Food } \\
\text { and Agriculture }\end{array}$ \\
\hline 2001 & $\begin{array}{l}\text { Doha Declaration on the TRIPS Agreement and Public } \\
\text { Health, specialized agencies of the United Nations system, } \\
\text { in particular, the Food and Agriculture Organization of the } \\
\text { United Nations (FAO) and the World Health Organization } \\
\text { (WHO) }\end{array}$ \\
\hline 2003 & International Declaration on Human Genetic Data \\
\hline 2005 & Universal Declaration on Bioethics and Human Rights \\
\hline
\end{tabular}

In the same way as UNESCO (2005), the Pan American Health Organization (PAHO), at the 28th Pan American Sanitary Conference in Washington, USA, whose theme was "Bioethics: for the integration of ethics in health" (PAHO, 2012), emphasized the importance of promote bioethics in order to safeguard the quality of research and respect for the dignity of the human being while respecting 
cultural diversity and the acquisition of knowledge, as well as its application in health decision making (PAHO, 2012). Also, according to this Conference (PAHO, 2012), the analysis Bioethics should be carried out in the light of fundamental values such as respect for their decision-making capacity based on their values and beliefs, the well-being of people and populations, and justice. As a reflexive activity, ethics always leads to a univocal answer. For PAHO (2012), bioethics explores ethical issues that arise in interventions in public health, health and health research. Bioethics is not an empirical discipline, because the empirical evidence of something does not determine that it is ethically correct. Bioethics is a discipline that consists of analytical activity and based on principles and ethical criteria that aims to guide the practice in the different areas of health. In this way, it is likely that there is more than one way of proceeding that is ethically correct. Also, the new technologies and the complexity of contemporary societies present a growing number of ethical problems that are increasingly complex. An analytical reflection is necessary for a rigorous and reasoned approach, in order to incorporate ethical considerations in health work (Carlotto and Dinis, 2019a).

\subsection{Casuistic Paradigm of Bioethics}

The paradigm of casuistic bioethics emerged between the sixteenth and seventeenth centuries as an alternative to the moral problems that arose with cultural, economic, political origins of the modern world. In this sense, this paradigm sought to analyze the concrete conjunctures to understand the new ethical dilemmas that presented and therefore investigated the most appropriate solutions by analogy (Junges, 2006). The authors Jonsen and Toulmin (1988) are the most traditional representatives of this paradigm, both of which were members of the Belmont Commission (1978). For these authors, the traditional casuistic paradigm is based on the rhetoric, in which they affirm that there is no possibility of constructing arguments without a clear view of the question to be analyzed from a particular point of view. From the analysis of these questions, the ethical dilemmas, the moral constitution and the search for the essence of the ethical issue raised. The cases or questions analyzed to become the legal principles in the discovery of the moral sense and the construction of moral certainty. On the other hand, the birth of the casuistic paradigm has become a focus of necessary questioning in the mainstream paradigm, and the four consecutive publications of the classic Principles of Biomedical Ethics, 2nd edition in 1983 (Beauchamp and Childress, 1983), 4th edition in 1994 (Beauchamp and Childress, 1994), 5th edition in 2001 (Beauchamp and Childress, 2001) and 7th edition in 2002 (Beauchamp and Childress, 2002), incorporated the principles with the analysis of the cases, in an integrated standard without, however, deny the primacy of principles (Beauchamp and Childress, 2001).

For Junges (2006), the weaknesses of the mainstream paradigm are the strengths of the paradigm, and the strengths of the principles are the weaknesses of case analysis casuist. On the other hand, one of the criticisms of the casuistic paradigm concerns the that determine a case to be analyzed, that is, the casuistic method does not compare the reality critically to be analyzed, however, eliminates the already established prejudices, at risk of becoming overly individualistic and subject to private judgment. As a complement to the casuistic paradigm and as support for the interpretation of cases, the hermeneutic dimension of bioethics arises, stating that human knowledge is interpretive by nature and, from this interpretation, it obtains meaning. In this context, bioethics acquires the role of reflection, appreciation and socio-cultural analysis, attribute of any ethical reflection (Junges, 2014).

\section{Bioethics as a reflective and inclusive tool in the promotion of teachers' health in higher education}

From the global political point of view, the objectives established by the Ottawa Charter (WHO, 1986) characterize as the guiding principle concerning the HP. Dooris et al (2012) argue that universities are relevant organizations for the $\mathrm{HP}$, not only as contexts aimed at improving well-being but also as multisectoral health partners that contribute to the development of citizenship and social change. The investment in HP and salutogenesis in the context of $\mathrm{HE}$ is valuable, given the specificities that are characteristic of this segment (Carlotto and Dinis, 2018c; Dooris et al., 2012; Kass, 2004; Pérez- 
Polanco and Montaño-Zetina, 2017). Dooris et al. (2012) propose that the analysis on the ecological and salutogenic model in HE should consider the multiplicity of roles of universities that act as centres of learning and development; as stimulators of creativity and innovation; as places where citizenship developed; and as resource mobilizers, investments and local, regional, national and global partnerships. This growing commitment to the incorporation of health and well-being into HE reinforces and instigates the development of sustainability in academic actions (HEFCE, 2014), broadening and qualifying the HP approach (Matisonn, 2017; Orme and Barna, 2010).

The idea of approaching health from promotion allows us to anticipate situations and change paths of action, in a healthy way, in all fields of public health (Li, 2017; Luken and Sammons, 2016), areas also defended by bioethics. In this conception, bioethics presents itself as a reflexive, mutually shared and interdisciplinary tool that aims at the adequacy of the health actions that make up life and citizenship, in the context of higher education and teaching, whose principles are strictly related to the approach of healthy universities (Dooris, 2005).

Coughlin (2008) and Dooris et al. (2017) emphasize and signal that ethical principles and values related to HP and bioethics actions, are characterized by their taxonomy and do not apply only to the biomedical field. Categories such as solidarity, public trust, autonomy/otherness, resilience, individual and community well-being, global health, shared commitment, inclusion and environmental health/sustainability identify a bioethical practice committed to the complexity of current events and the search for balanced answers to the conflicts presented (Campos Daniel et al., 2016; Carlotto and Dinis, 2018b; Coughlin, 2008; Garrafa, 2005b; Petrini, 2013; Petrini, 2015). On the other hand, bioethics, as an analytical and principle-based activity, seeks to reflect on the teaching of the HP in educational institutions, contributing for the construction of qualified processes of actions in obtaining health processes of teachers (PAHO, 2012).

However, some challenges anticipated from this perspective: (i) the need for formulation and implementation of public policies that contemplate the HP approach in HE, while investing, resources and strengthening positive assets for planned actions in health; (ii) health and bioethics acting as interdisciplinary and transversal themes with other disciplines; (iii) development of a health-oriented approach salutogenesis; (iv) strengthening the role of teaching in HE, encouraging health actions wellbeing, cohesion, inclusion, sustainability, social justice and dignity (Carlotto and Dinis, 2017a; Dooris et al., 2017). It is therefore apparent that bioethics is based on the perception that every human being is a relational being, with individual and plural peculiarities. The humanization can only occur through the awareness of the importance of social interaction. In the recognition process as a person, the individual seeks the understanding and development of characteristics of respect and autonomy with oneself and with others, allowing to interpret, reflect and recognize ethics and bioethics in their relationships (Oliveira, 2015).

From this hypothesis, it is clear that the characteristic of transversality that characterizes bioethical principles allows us to consider this discipline as an essential tool of conduct in the teacher's $\mathrm{HP}$ actions, contributing to the bright and reflective understanding of the healthy role of teachers in universities (Carlotto and Dinis, 2017a; CMHA, 2018; Dooris, 2016). In order to consolidate and promote advances regarding the use of the bioethical paradigm in HP actions, it is essential to clarify the role of bioethics in its strict sense, indicating its possibilities of operationalization in the areas of health workers, and to ensure integration of ethics and bioethics into academic curricula.

In this way, in order to incorporate ethics substantially and systematically in the different health areas and the disciplines of the HEI common tree, several mechanisms are proposed such as (i) strengthening and emphasizing the application of bioethical analysis in everyday situations involving the reflection of ethical dilemmas; (ii) to continually identify and evaluate health training needs that combine bioethical principles, the specific activities of the target populations and their singularities; (iii) closer relations with critical organs and that serve as a reference in this area, for example, coordination of the Regional Program on Bioethics and Ethics of the World Health Organization (WHO), Collaborating Regional Bioethics Centers (PAHO) and Bioethics Program of UNESCO (PAHO, 2012). Transversity, in turn, becomes a viable alternative to the more sophisticated perception of reality and the challenges that manifested in the context of the HP teacher, under the bioethical approach. 
According to Junges (2006), bioethics is a paradigm-action model that contextualizes the ethical reaction directed to the knowledge of the human being and the natural environment. In this way, the role of transversality presented with a hermeneutic dimension that, interrelated, promote ethical and reflexive responses to scientific knowledge and the challenges posed by contemporary biotechnological dimensions.

\section{Results}

The general profile of the sample points to the following data: $14 \%$ of the teachers ( $n=199)$ were admitted to HEIs surveyed in the early $2000 \mathrm{~s}, 87 \%$ of which $(n=1219)$ were linked to private HEI. $76 \%$ belong to the female gender $(n=1070), 53.7 \%$ between the ages of 46 and $55(n=752)$. The Health Sciences training area accounts for $67.3 \%$ of respondents $(n=943)$, followed by the area of Engineering $(n=142)$ and Human Sciences $(n=109)$. The level of schooling comprises $75 \%$ Doctors $(n=1046)$ and $19 \%$ Masters $(n=266) .60 .3 \%(n=845)$ had 15 to 20 years of teaching experience, and the weekly workload worked at $26.2 \%$ for 40 hours per week $(n=368), 16.1 \%$ for 20 hours $(n=226)$ and $13.5 \%$ for 30 hours per week $(n=189)$. Of the 1400 teachers surveyed, $79.5 \%$ have a single employment relationship $(n=1113)$. The table 2 shows the socio-demographic characteristics of the teachers analysed in the research.

Table 2. Socio-demographic characteristics of teachers.

\begin{tabular}{|c|c|c|}
\hline \multicolumn{3}{|c|}{ Socio-demographic characteristics of teachers } \\
\hline \multirow[b]{2}{*}{ Characteristics } & \multicolumn{2}{|c|}{ Respondents } \\
\hline & $n$ & $\%$ \\
\hline \multicolumn{3}{|l|}{ Age } \\
\hline $26-30$ years & 106 & 8 \\
\hline $31-35$ years & 143 & 10 \\
\hline $36-45$ years & 215 & 15 \\
\hline $46-55$ years & 752 & 54 \\
\hline+55 years & 184 & 13 \\
\hline \multicolumn{3}{|l|}{ Marital status } \\
\hline Married / companion & 1080 & 77 \\
\hline Separated / divorced & 159 & 11,8 \\
\hline Single Children: & 156 & 11 \\
\hline Widowed & 3 & 0,2 \\
\hline \multicolumn{3}{|c|}{ Degree of education / schooling } \\
\hline Doctor & 1046 & 75 \\
\hline Specialist & 35 & 2 \\
\hline Master & 266 & 19 \\
\hline Post doctor & 50 & 3 \\
\hline Other training & 3 & 1 \\
\hline \multicolumn{3}{|l|}{ Gender } \\
\hline Male & 330 & 24 \\
\hline Female & 1070 & 76 \\
\hline
\end{tabular}


Through the applied factorial analysis and the Varimax ${ }^{\circledR}$ rotation it was possible to extract six main components, according to table 3 .

Table 3. Estimated six factor loads (frequencies) after the Varimax ${ }^{\circledR}$ rotation with Kaiser normalization for the answers to the instrument questions/ $R$ Development Core Team (2015)

\begin{tabular}{|c|c|c|c|c|c|c|c|}
\hline \multirow[t]{2}{*}{ Questions } & \multicolumn{6}{|c|}{ Factors } & \multirow[t]{2}{*}{ Variability Ratios } \\
\hline & 1 & 2 & 3 & 4 & 5 & 6 & \\
\hline Q8 & $-0,578$ & 0,170 & 0,186 & $-0,329$ & 0,095 & 0,328 & 0,622 \\
\hline Q10 & $-0,645$ & $-0,180$ & $-0,175$ & 0,482 & 0,002 & $-0,161$ & 0,737 \\
\hline Q11 & 0,587 & 0,405 & 0,038 & $-0,283$ & $-0,378$ & 0,189 & 0,769 \\
\hline Q13 & 0,572 & 0,370 & $-0,014$ & $-0,299$ & $-0,268$ & 0,097 & 0,635 \\
\hline Q16 & 0,826 & 0,320 & 0,007 & 0,003 & 0,358 & $-0,110$ & 0,924 \\
\hline Q23 & 0,812 & 0,069 & 0,049 & 0,094 & 0,339 & $-0,134$ & 0,808 \\
\hline Q24 & 0,786 & 0,309 & 0,015 & $-0,064$ & $-0,195$ & 0,063 & 0,760 \\
\hline Q26 & 0,827 & 0,163 & 0,187 & $-0,194$ & 0,263 & 0,000 & 0,852 \\
\hline Q28 & 0,855 & 0,253 & $-0,065$ & $-0,004$ & $-0,177$ & 0,036 & 0,833 \\
\hline Q31 & 0,847 & 0,331 & 0,054 & $-0,042$ & $-0,100$ & 0,114 & 0,854 \\
\hline Q32 & 0,895 & 0,206 & 0,081 & $-0,115$ & $-0,039$ & 0,032 & 0,866 \\
\hline Q19 & 0,037 & 0,602 & $-0,569$ & $-0,154$ & $-0,127$ & 0,013 & 0,728 \\
\hline Q21 & 0,253 & 0,776 & 0,109 & $-0,155$ & $-0,134$ & $-0,014$ & 0,719 \\
\hline Q22 & 0,313 & 0,719 & $-0,295$ & $-0,033$ & $-0,176$ & 0,028 & 0,735 \\
\hline Q25 & 0,068 & 0,626 & 0,528 & $-0,298$ & 0,010 & 0,150 & 0,787 \\
\hline Q27 & 0,164 & 0,757 & 0,217 & $-0,342$ & $-0,021$ & 0,020 & 0,765 \\
\hline Q29 & 0,334 & 0,800 & 0,104 & $-0,001$ & $-0,207$ & 0,077 & 0,811 \\
\hline Q30 & 0,306 & 0,847 & 0,060 & $-0,150$ & $-0,056$ & 0,005 & 0,841 \\
\hline Q33 & 0,379 & 0,814 & 0,030 & $-0,088$ & 0,026 & $-0,024$ & 0,816 \\
\hline Q6 & $-0,265$ & 0,174 & 0,648 & $-0,064$ & $-0,145$ & 0,101 & 0,555 \\
\hline Q7 & $-0,187$ & 0,177 & $-0,662$ & $-0,028$ & $-0,104$ & 0,409 & 0,684 \\
\hline Q9 & 0,344 & $-0,085$ & 0,602 & $-0,028$ & $-0,258$ & 0,154 & 0,579 \\
\hline Q18 & 0,104 & $-0,132$ & $-0,659$ & $-0,385$ & $-0,056$ & 0,033 & 0,615 \\
\hline Q35 & 0,361 & 0,304 & 0,631 & $-0,272$ & 0,030 & 0,032 & 0,697 \\
\hline Q15 & 0,044 & $-0,210$ & $-0,055$ & 0,703 & 0,423 & 0,076 & 0,727 \\
\hline Q20 & $-0,202$ & $-0,201$ & 0,167 & 0,764 & 0,001 & 0,126 & 0,709 \\
\hline Q34 & $-0,061$ & $-0,380$ & $-0,072$ & 0,751 & 0,354 & 0,023 & 0,843 \\
\hline Q14 & 0,022 & $-0,106$ & 0,096 & 0,334 & 0,764 & $-0,089$ & 0,724 \\
\hline Q17 & 0,179 & $-0,391$ & $-0,208$ & 0,122 & 0,716 & $-0,049$ & 0,758 \\
\hline Q1 & $-0,139$ & 0,104 & 0,045 & 0,162 & 0,268 & 0,618 & 0,513 \\
\hline Q2 & 0,099 & 0,055 & 0,010 & 0,202 & $-0,009$ & 0,610 & 0,426 \\
\hline Q4 & $-0,099$ & 0,122 & 0,102 & 0,275 & 0,066 & $-0,497$ & 0,361 \\
\hline Q5 & 0,012 & $-0,382$ & $-0,181$ & $-0,090$ & $-0,274$ & 0,548 & 0,563 \\
\hline $\begin{array}{c}\text { Number of } \\
\text { items }\end{array}$ & 11 & 9 & 7 & 4 & 3 & 5 & \\
\hline Eigenvalues & 7,341 & 6,020 & 3,069 & 3,007 & 2,384 & 1,796 & \\
\hline
\end{tabular}




\begin{tabular}{|c|c|c|c|c|c|c|c|}
\hline \multirow[t]{2}{*}{ Questions } & \multicolumn{6}{|c|}{ Factors } & \multirow[t]{2}{*}{ Variability Ratios } \\
\hline & 1 & 2 & 3 & 4 & 5 & 6 & \\
\hline Variance $(\%)$ & 31,084 & 25,491 & 12,994 & 12,734 & 10,092 & 7,603 & \\
\hline $\begin{array}{l}\text { Cumulative } \\
\text { variance (\%) }\end{array}$ & 21,18 & 38,48 & 47,74 & $56,33 \%$ & 63,66 & 69,20 & \\
\hline$\alpha$ & 0,802 & 0,925 & 0,638 & 0,823 & 0,765 & 0,752 & Average 0,80 \\
\hline
\end{tabular}

The table 4 shows the higher factor loads that emerged from the extraction of each component and the number of variables that formed each component. The extracted components are directly proportional to the original categories of the Toolkit Self-review tool, which served as the theoretical basis for this work.

Table 4. Categories that emerged from the questionnaire/Six main components/MAXQDA ${ }^{\circledR}(2018)$

\begin{tabular}{|c|c|c|}
\hline Categories/Main Components & Number & $\begin{array}{r}\text { Higher factor load } \\
\text { of variables in } \\
\text { component composition }\end{array}$ \\
\hline $\begin{array}{l}01 \text { - Programs and activities to } \\
\text { support health and sustainable } \\
\text { development }\end{array}$ & 0,895 & 11 \\
\hline $\begin{array}{l}02 \text { - Facilities and environments } \\
\text { conducive to HP/ Information and } \\
\text { Communication Technologies } \\
\text { (ICTs) }\end{array}$ & 0,847 & 9 \\
\hline $\begin{array}{l}03 \text { - Development of actions of health } \\
\text { and well-being at work through a } \\
\text { comprehensive and integral approach } \\
\text { / Bioethics }\end{array}$ & 0,64 & 7 \\
\hline $\begin{array}{l}04-\text { Key contacts / support services / } \\
\text { dissemination of institutional } \\
\text { research in health and sustainability }\end{array}$ & 0,648 & 4 \\
\hline $\begin{array}{l}05 \text { - Referrals and clarifications of } \\
\text { health problems / accessibility }\end{array}$ & 0,764 & 3 \\
\hline $\begin{array}{l}06 \text { - Strategic planning / impact } \\
\text { assessment / partnerships }\end{array}$ & 0,618 & 5 \\
\hline
\end{tabular}




\section{Discussion}

Using the Ottawa Charter (WHO, 1986) as a starting point, health is considered a multidimensional (physical, mental, emotional, spiritual, social) resource for life. The focus for the establishment of an ecological and salutogenic paradigm in HP is not only to identify needs, behaviour change and disease prevention, but also to promote and strengthen assets and resources for health, well-being and prosperity (Dooris et al., 2012). HP values the interactions of the individual with the social environments and, in this approach, the ecological models present as a possibility of development of health actions in a holistic, sustainable and salutogenic way, stimulating positive aspects related to ethics, well-being, quality of life and happiness (Dooris et al., 2017).

The main objective of HP teachers in HE is to combine these models with the autonomy derived from necessary health actions: investigate and visualize the gaps in which HP can, through interdisciplinarity, strengthen relationships and produce health, well-being and quality of life for teachers, relevant indicators in public health. The university environment can be understood as a social system in its totality, with its interrelations between the parts and the whole. This system is complex and dynamic being in balance or change, with elements affected by feedback cycles in constant motion. When applied to teacher health, this theory illustrates that healthy structures (e.g., adoption of a strategic plan and management commitment) are a precondition for healthy processes (e.g. effective communication and efficient management are both, preconditions for health outcomes and are therefore determinants of health (Dooris et al., 2012).

The results of this study point out that in addition to the HP principles generally identified in the literature, such as equity, interdisciplinarity, participation and holism, additional principles related to the HP teacher in HE has been identified. Teachers evoked concepts such as solidarity, public trust, autonomy, resilience, individual and community well-being, global health, shared the commitment and environmental health/sustainability researched, impacting overall health, individual and collective well- inclusion and social justice of teachers. Universities function as research and learning venues for sustainable development, stimulating HP's activities. On the other hand, the diffusion of HP's ecological models as an interdisciplinary and principle-based activity seeks to reflect on HP professor's at HEI, contributing to the construction of qualified processes of actions in HP professor's. In this perspective, the interdisciplinarity proposed by bioethics becomes a tool for the recognition of shared goals, the need for consideration of plural knowledge, inclusion and reflection. In addition to the mainstream paradigm established by bioethics, e.g., charity, nonmaleficence, justice and respect for autonomy (Beauchamp and Childress, 1979), underlying references such as solidarity, shared commitment and health sustainability were evoked by the teachers surveyed, resulting in an impact positive impact on $\mathrm{HP}$, both at the individual and collective levels, quality of life, inclusion and social justice in the university environment. The principles of bioethics and ecological models integrated in the sense of objectifying the construction of a more humanized HP model and assuming the exercise of health care in HE in an interdisciplinary and socially responsible way.

By valuing and understanding the interrelationships, interactions and synergies in the university environment, derived from interdisciplinary practices, a clear commitment conceived with $\mathrm{HP}$ in HE. Stimulating healthy working and learning environments leads to the sustainable development of educational processes and the exchange of knowledge, as well as to increased health and well-being, reinforcing the commitment to health, sustainability and equity of teachers. In this 
way, we seek to interface teachers' ecological and salutogenic HP models using bioethics as a useful intervention tool, and reflect on how it is possible to contribute to stimulating adequate and inclusive health actions for teachers in the academic environment, visualizing the health as an integral part of the university's culture, structure and processes (Carlotto and Dinis, 2017a).

Among the limitations of this study, it is possible to emphasize the need for public policy formulation and morally justifiable decision making for HP teacher's from the bioethical perspective, integrating health and teaching staff in an interdisciplinary way, identifying opportunities that encourage well-being and commitment to the health of teachers; to develop the ecological and salutogenic approach in HE through the encouragement of evidence-informed research and action; recognize HP teacher's in HE as an investment and resource needed to strengthen positive assets for planned health actions (Carlotto and Dinis, 2019b).

\section{Materials and Methods}

The research had a cross-sectional design with the quantitative and qualitative approach, of exploratory-descriptive nature (Prodanov, 2013). The population composed by teachers from HEI of the State of Rio Grande do Sul (RS) / Brazil, selected by random, non-probabilistic sampling for convenience (openepi $=95 \%$ CI (\%), $n=1400$ individuals). Data collection performed between March and July 2017. The present study was approved by the Research Ethics Committee of the Hospital de Clínicas of Porto Alegre (HCPA) / Brazil, by the Ethics Commission of the University Fernando Pessoa (UFP) Porto / Portugal, and by the Brazil Platform CAAE 550666168.0000.5327. For data collection, an online survey was built hosted on the Survio ${ }^{\circ}$ platform and sent to the participants of the research by e-mail. Previously, contact was made with the leaders of each HEI to present the research objective and obtain approval for the applicability of the survey. All the respondents were informed about the fundamental science of the Free and Informed Consent Form (FICF) accompanying the protocol. The statistical analysis of the results was carried out with the aid of the statistical software environment $R^{\circledast}(R$ Development Core Team), version 3.3.1. (2015); through crosschecking of survey data and the conceptual frameworks of the Health Promoting Universities (HPU) / World Health Organization (WHO). Qualitative dissertation data treated with Content Analysis, according to Bardin (2009) and software MAXQDA ${ }^{\circledR}$ (2018).

The data were collected and worked by the Researcher, through the application of 1400 questionnaires, each containing 35 questions, each question with five answers, each answer being evaluated by a Likert scale with attribution of the following values by the Researcher: 1 point - I do not know fully; 2 points - partially unknown; 3 points - I know; 4 points - I know partially and 5 points - I totally know. The instrument was an adaptation of the Toolkit - HPU / WHO protocol of the University of Lancashire-Lancaster / UK, expressly authorized by its idealizer, Professor Mark T. Dooris. The Toolkit includes a research tool that enables HEIs to analyze and reflect on their perception of health, sustainable development, and well-being in their core business and organizational culture. The significance level of $1 \%$ was adopted, rejecting hypotheses whose descriptive value ( $p$-value) was lower than 0.001 ; Varima ${ }^{\circledR}$ rotation with factorial load retention> 0.40 was used; the analysis of Factors and Analysis of Main Components (AMC) with an eigenvalue higher than 1.0 was applied to identify groups or groupings of variables, and thus to understand the structure of a set of variables and to show the relations between them, reducing the data set to a more 
manageable size while retaining as much of the original information as possible. Cronbach's alpha (acceptable index $>0.60$ ) ensured the internal consistency of the instrument used.

\section{Conclusions}

HE has a vital role to play. Universities function as places of research and learning for sustainable development, stimulating health promotion activities. In this proposal, Bioethics, as an analytical and principle-based activity, seeks to reflect on HP in HEI, contributing to the construction of qualified processes of actions in teacher's health, with the proper conceptual clarity that characterizes this bioethical process (PAHO, 2012).

Possible practical implications: need for public policy formulation and morally justifiable decision making addressed to HP teacher's under an ecological and salutogenic approach; integrating the health and education team, identifying opportunities that support the well-being and commitment to the health of teachers from a bioethical perspective; develop the salutogenic approach in HE, promoting research and action informed by evidence; recognize HP teacher's in HE as an investment and resource needed to strengthen positive assets for planned health actions (Carlotto and Dinis, 2019b).

Author Contributions: The authors contributed equally to the research work in the following aspects: conceptualization; methodology; validation; formal analysis; investigation; resources; writing-original draft preparation; writing - review and editing; visualization; supervision; project administration and submission.

Funding: This research received no external funding.

Acknowledgments: FP-ENAS (UFP), Porto, Portugal; Ethics committee University Fernando Pessoa (UFP), Porto, Portugal; Ethics committee Hospital de Clínicas de Porto Alegre (HCPA), Brazil; Professor Mark. T. Dooris (UCLan,UK); Sociedade Brasileira de Bioética (SBB), Brazil; Fundação para a Ciência e Tecnologia (FCT), Portugal.

Conflicts of Interest: The authors declare no conflict of interest.

\section{References}

Azetsop, J. 2011. New directions in African bioethics: ways of including public health concerns in the bioethics agenda. Development World of Bioethics 11: 4-15. Doi: 10.1111/j.1471-8847.2009.00271. x

Bardin, L. 2009. Análise de conteúdo. Lisboa : Edições 70.

Beauchamp, T. L. and Childress, J. F. 1979. The principles of biomedical ethics, 1st ed. New York: Oxford. Beauchamp, T. L. and Childress, J. F. 1983. The principles of biomedical ethics, 2nd ed. New York: Oxford. Beauchamp, T. L. and Childress, J. F. 1994. The principles of biomedical ethics, 4th ed. New York: Oxford. Beauchamp, T. L. and Childress, J. F. 2001. The principles of biomedical ethics, 5th ed. New York: Oxford. Beauchamp, T. L. and Childress, J. F. 2002. The principles of biomedical ethics, 7th ed. New York: Oxford.

Campos Daniel, J., Dias Reis Pessalacia, J. and Leite de Andrade, A. F. 2016. Interdisciplinary debate in the teaching-learning process on bioethics: academic health experiences. Investigación y educación en enfermeira 34: 288-296. Doi: 10.17533/udea.iee.v34n2a08

Carlotto, I. N. and Dinis, M. A. P. 2017a. Bioética como contribuição transversal para a promoção da saúde de docentes na educação superior. In XII Congresso Brasileiro de Bioética e IV Congresso Brasileiro de Bioética Clínica. Paper presented at XII Congresso Brasileiro de Bioética e IV Congresso Brasileiro de Bioética Clínica, Recife/Brazil, 26-29 September 2017. Sociedade Brasileira de Bioética - SBB/Conselho Federal de Medicina - CFM. Available online http://www.cbbioetica.com.br/arqTrabalho/trabalhosApresentacaoOral.pdf.

Carlotto, I. N. and Dinis, M. A. P. 2017b. Bioética e Promoção da Saúde Docente na Educação Superior: Uma Interface Necessária. Revista Saber E Educar 23: 168 - 179.

Carlotto, I. N. and Dinis, M. A. P. 2018a. Bioética e Cuidado de Enfermagem na promoção da saúde de docentes na educação superior. In 12th International Seminar on Nursing Research Proceedings. Paper presented at 12th 
International Seminar on Nursing Research, Porto/Portugal, 03-04 May 2018. ISBN 978-989-97041-8-3. Available online http://www.saude.porto.ucp.pt/isnr?msite=17

Carlotto, I. N. and Dinis, M. A. P. 2018b. Building bridges between bioethics and ecological models of health promotion in higher education. In CUICIID 2018 (Congreso Universitario Internacional sobre la comunicación en la profesión y en la Universidad. de hoy: Contenidos, Investigación, Innovación y Docencia). Paper presented at CUICIID 2018, Madrid/Spain, 24-25 October 2018. ISBN 978-84-09-04679-9. Available online www.seeci.net/cuiciid.

Carlotto, I. N. and Dinis, M. A. P. 2018c. Bioethics as a paradigm for health promotion in higher education: a cross-sectional study. In UNESCO Chair in Bioethics 13th World Conference Bioethics, Medical Ethics and Health Law. Paper presented at UNESCO Chair in Bioethics 13th World Conference Bioethics, Medical Ethics and Health Law, Jerusalem/Israel, 27-29 November 2018. Available online https://ethics-2018.isas.co.il/wpcontent/uploads/sites/35/2018/12/Ethics-2018-Abstract-book.pdf

Carlotto, I. N. and Dinis, M. A. P. 2019a. Tecnologias da informação e comunicação (TICs) na promoção da saúde: considerações bioéticas. Revista Saber E Educar 25. Doi: 10.17346/se.vol24.306. In press.

Carlotto, I. N. and Dinis, M. A. P. 2019b. Building bridges between bioethics and ecological models of health promotion in higher education. In CUICIID 2018 (Congreso Universitario Internacional sobre la comunicación en la profesión y en la Universidad. de hoy: Contenidos, Investigación, Innovación y Docencia). Paper presented at CUICIID 2018 (Congreso Universitario Internacional sobre la comunicación en la profesión y en la Universidad. de hoy: Contenidos, Investigación, Innovación y Docencia), Madrid/Spain, 24-25 October 2018. Conference Proceedings Scopus and Clarivate. ISBN 978-84-09-04967-7. Available online http://www.seeci.net/cuiciid/. In press.

CMHA. Canadian Mental Health Association. 2018. Healthy minds, healthy campuses initiative. Canada: BC Ministry of Health.

Coughlin, S. S. 2008. How Many Principles for Public Health Ethics? Open Public Health Journal 1: 8-16. Doi: 10.2174/1874944500801010008

Dooris, M. 2005. Healthy settings: challenges to generating evidence of effectiveness. Health Promotion International 21: 55-65.

Dooris, M. 2006. Healthy settings: challenges to generating evidence of effectiveness. Health Promotion International 21: 55-65. Doi: 10.1093/heapro/dai030

Dooris, M. 2016. International perspectives on healthy settings: critical reflections, innovations and new direction. Global Health Promotion 23: 5-7.

Dooris, M. 2016. International perspectives on healthy settings: critical reflections, innovations and new direction. Global Health Promotion 23: 5-7.

Dooris, M., Doherty, S. and Orme, J. 2017. The application of salutogenesis in universities. In The Handbook of Salutogenesis. England: Springer, pp.237-245.

Dooris, M., Doherty, S., Cawood, J. and Powell, S. 2012. The Healthy Universities approach: Adding value to the higher education sector. In The Health promotion settings: Principles and practice. London: Sage.

Doran, K., Resnick, B., Kim, N., Lynn, D. and McCormick, T. 2017. Applying the Social Ecological Model and Theory of Self-Efficacy in the Worksite Heart Health Improvement Project-PLUS. Research and Theory for Nursing Practice 31: 8-27. Doi: 10.1891/1541-6577.31.1.8

Duarte-Cuervo, C. Y. 2015. The understanding and implementation of health promotion at higher education institutions in Colombia. Revista de Salud Publica (Bogota) 17: 899-911. Doi: 10.15446/rsap. v17n6.44713

García, J. J. 2013. Principialistic and personalistic bioethics. Some perspectives. Cuadernos de Bioética 24: 67-76.

Garrafa, V. 2005a. Inclusão social no contexto político da bioética. Revista Brasileira de Bioética 1: 122-132.

Garrafa, V. 2005b. Inclusão social no contexto político da bioética. Revista Brasileira de Bioética 1: 122-132.

HEFCE. Higher Education Funding Council for England. 2014. Sustainable development in higher education. England: HEFCE's.

Hellegers, A., and Ramsey, P. 1973. The patient as person. In The Explorations in medical ethics. Connecticut: New Haven.

Jonsen, A. R. and Toulmin, S. 1988. The abuse of casuistry. A history of moral reasoning. Los Angeles: Press.

Junges, J. R. 2006. Bioética: hermenêutica e casuística. São Paulo: Loyola.

Junges, J. R. 2014. Bioética sanitarista: desafios éticos da saúde coletiva. São Paulo: Loyola.

Kass, N. E. 2004. Public health ethics: from foundations and frameworks to justice and global public health. The Journal of Law, Medicine E Ethics 32: 232-242, 190.

Li, M. Y. 2017. Occupational mental health and job satisfaction in university teachers in Shen-yang, China. Zhong Lao Dong Wei Sheng Zhi Ye Bing Za Zhi 35: 137-140.

Luken, M. and Sammons, A. 2016. Systematic Review of Mindfulness Practice for Reducing Job Burnout. The Am Journal of Occupational Therapy 70: 2. Doi: 7002250020p7002250021-7002250020p7002250010 
Mandal, J., Ponnambath, D. K. and Parija, S. C. 2017. Bioethics: A brief review. Tropical Parasitology 7: 5-7. Doi: $10.4103 /$ tp.TP_4_17

Matisonn, H. 2017. Bioethics: A Philosophical Introduction. In The Book Review. Cambridge: Polity Press.

MAXQDA. 2018. The art of data analysis. Available online https://www.maxqda.com/?utm_expid=.HYL6SEWUQaqlYvgzfnwOzA.0\&utm_referrer=https\%3A\%2F\% 2Fwww.maxqda.com\%2Fwhat-is-maxqda (accessed on 16 August 2018).

Oliveira, C. C. 2015. Suffering and salutogenesis. Health Promotion International 30: 222-227. Doi: 10.1093/heapro/dau061

Oliveira, R. A. 2012. Bioética. Revista Brasileira de Psicanálise 46: 105-117.

Orme, J. and Barna, S. 2010. Education for sustainable development: The role of Healthy Universities. Healthy Universities Issue. Consulted in 10/06/2017, available in: http://www.healthyuniversities.ac.uk/

PAHO. Pan American Health Organization. 2012. Regional program on bioethics. Available online http://www.paho.org/hq/index.php?option=com_content\&view=article\&id=5582\%3A2011-regionalprogram-on-bioeth-ics\&catid=3347\%3Abioethics\&Itemid=4124\&lang=es (accessed on 05 February 2017).

Parker, E., Gould, T. and Fleming, M. 2007. Ethics in health promotion-reflections in practice. Health Promotion Journal of Australia 18: 69-72.

Pérez-Polanco, P. and Montaño-Zetina, L. M. 2017. The importance of promoting the bioethical seeds in the University. Revista Médica del Instituto Mexicano del Seguro Social 55: 104-109.

Petrini, C. 2013. Ethics in public health surveillance. Annali dell'Istituto Superiore di Sanità 49: 347-353. Doi: 10.4415/ANN_13_04_05

Petrini, C. 2015. A framework for evaluating ethical issues of public health initiatives: practical aspects and theoretical implications. Ig Sanita Pubblica 71: 327-334.

Potter, V. R. 1971. Bioethics, bridge to the future. Englewood Cliffs: Prentice Hall.

Prodanov, C.C. 2013. Metodologia do trabalho científico: métodos e técnicas da pesquisa e do trabalho acadêmico. 2nd ed. Novo Hamburgo: Feevale.

$R$ Development Core Team. 2015. $R$ : a language and environment for statistical computing. R Foundation for Statistical Computing. Vienna, Austria. Available online https://www.gbif.org/tool/81287/r-a-languageand-environment-for-statistical-computing (accessed on 16 July 2017).

Real de Asúa, D. and Herreros, B. 2016. Why dedicate yourself to bioethics? Seven reasons to get you started. Revista Clínica Española 216: 271-275. Doi: 10.1016/j.rce.2015.12.003

Santana, J. P. and Garrafa, V. 2013. Cooperation in health from the bioethical perspective. Ciência e Saúde coletiva 18: 129-137. Doi: 10.1590/S1413-1232013000100014

Sanz, E. J. 2016. Day to day bioethics: Beyond the experts. Revista Clínica Española 216: 255-256. Doi: 10.1016/j.rce.2016.03.004

Siqueira-Batista, R., Gomes, A. P., Motta, L. C. S., Rennó, L., Lopes, T. C., Miyadahira, R., Vidal, S. V. and Cotta, R. M. M. 2015. (Bio)ética e Estratégia Saúde da Família: mapeando problemas. Saúde e Sociedade 24: 02-16. Doi: 10.1590/S0104-12902015000100009

Snead, O. C. 2009. Bioethics and self-governance: the lessons of the Universal Declaration on Bioethics and Human Rights. Journal of Medicine and Philosophy 34: 204-222. Doi:10.1093/jmp/jhp024

U. S. Government. 1978. The Belmont Report: Ethical guidelines for the protection of human subjects. Washington: DHEW Publications.

UNESCO. United Nations Educational, Scientific and Cultural Organization. 2005. Universal Declaration on Bioethics and Human Rights. Available online http://unesdoc.unesco.org/images/0014/001461/146180por.pdf (accessed on 31 October 2017).

WHO. World Health Organization. 1986. Ottawa Charter for Health Promotion. Geneva.

Zoboli, E. L. C. P. 2010. Relación clínica y problemas éticos en atención primaria, São Paulo, Brasil. Atención Primaria 42: 406-412. Doi: 10.1016/j.aprim.2010.01 